\title{
Influence of the Passive Design of a Building Facade on the Indoor Thermal Comfort of Residential Buildings
}

\author{
Zhou Pengfei ${ }^{1}$, Zhang $\mathrm{Chi}^{1}$, and Jiang Wang ${ }^{2}$ \\ ${ }^{1}$ Faculty of Built Environment, University of New South Wales, Sydney, Australia \\ ${ }^{2}$ Faculty of Built Environment, Yancheng Institute of Technology, Yancheng, China
}

\begin{abstract}
Building facades have evident effects on indoor thermal comfort. Hence, on the basis of a multifunctional residential building in Sydney, Australia, this research uses DesignBuilder software to optimize passive system design on building facades. This research also analyses the influences of changing window glazing type, adding additional shading devices and changing the material of the exterior wall on indoor thermal comfort. Results show that the number of uncomfortable hours can be reduced by 446,186 and 874 hours by using a double-layer Low-E glass, adding extra shading device and adopting an external wall material with low thermal conductivity, respectively. When the three aforementioned passive design strategies are combined, indoor thermal environment discomfort time can be reduced by $24 \%$. Therefore, the indoor thermal comfort of a building can be considerably improved through effective passive designs of the building facade.
\end{abstract}

\section{Introduction}

The operation stage of a building accounts for a higher proportion of its entire life cycle compared with the architecture design and construction stages. Therefore, energy consumption during a building's operation stage comprises a major part of its energy consumption in its entire life cycle ${ }^{[1]}$. With the global energy crisis becoming increasingly serious, ensuring and improving indoor thermal comfort whilst reducing energy consumption during a building's operation stage are important goals ${ }^{[2]}$. At present, energy conservation in most buildings is focused on reducing energy consumption, whereas indoor thermal comfort is less frequently considered ${ }^{[3]}$.

Building facades affect indoor thermal comfort. The dual effects of reducing building energy consumption and improving indoor thermal comfort can be achieved by adopting a passive design in a reasonable manner. In this study, a passive design is applied to a multifunctional residential building in Sydney, Australia to optimize its facade. The computer simulation software DesignBuilder is used to simulate indoor thermal comfort during the operation stage $\mathrm{e}^{[4]}$. Corresponding passive construction optimization strategies are proposed based on the analyses of factors that influence the original indoor thermal comfort of a building. Subsequently, indoor thermal comfort is simulated and analysed after adopting passive optimization strategies. Without increasing energy consumption, passive design strategies on the facade are optimized and the indoor thermal comfort of the building is improved. This study provides references for the design and construction of local buildings of the same type.

\section{Project overview}

A multifunctional residential building with eight stories located in Bondi Beach $\left(33^{\circ} 89^{\prime} \mathrm{S}, 151^{\circ} 27^{\prime} \mathrm{E}\right)$ is selected as the research case. The project location exhibits the characteristics of a subtropical humid monsoon climate. The annual mean temperature in the region is $20.7^{\circ} \mathrm{C}$. July is the coldest month, with a mean temperature of $8^{\circ} \mathrm{C}$. January is the warmest month, with a mean temperature of $19{ }^{\circ} \mathrm{C}^{[5]}$. As shown in Figure 1, the building faces northwest, with an area of $2961 \mathrm{~m}^{2}$. Natural ventilation is adopted in the entire building, with no heating or refrigeration equipment. The building design meets the requirements of the Building Codes of Australia (BCA). This study develops optimization

design based on three factors that are closely related to building facades: facade glazing, shading devices and exterior wall materials. This study also uses DesignBuilder software for quantitative simulation analysis and the comparison of indoor thermal comfort before and after implementing the optimization design. Meanwhile, the new building energy efficiency design ASHRAE standard 55-2013 ${ }^{[6]}$, which stipulates that the total time should be within the acceptable temperature range, is used to evaluate indoor thermal comfort. Thermal comfort is the mental state that shows satisfaction with the thermal environment. It is evaluated based on the ASHRAE Standard, which points out that in a neutral environment (i.e. wind speed lower than $0.2 \mathrm{~m} / \mathrm{s}$, indoor humidity of $50 \%$ ), the comfortable temperature range during winter is $20^{\circ} \mathrm{C}-24{ }^{\circ} \mathrm{C}$ and that during summer is $24{ }^{\circ} \mathrm{C}-27{ }^{\circ} \mathrm{C}$. However, this standard is influenced by

\footnotetext{
* Corresponding author: yczpf1412956361@qq.com
} 
individual activities, clothing and outdoor temperature and humidity. Therefore, inhabitants living under natural ventilation are more likely to accept a wider temperature range, combine indoor comfortable temperature with outdoor temperature, and define $80 \%$ and $90 \%$ acceptability limits as satisfactory temperature range, as shown in Figure 2. On the basis of an experimental analysis, the aforementioned range is the range of thermal comfort, and any point outside this range will cause thermal discomfort. In the current experiment, the total time of indoor thermal comfort of a building with natural ventilation is used as the test datum, and the satisfactory range for $90 \%$ acceptability of the inhabitants in ASHRAE Standard 55-2013 is adopted as the acceptable temperature range.

A software analysis is performed based on the satisfactory temperature range for $90 \%$ of the inhabitants in ASHRAE Standard 55-2013. A conclusion is drawn that in the satisfactory temperature range, the uncomfortable time that does not meet this criterion is the uncomfortable time of the indoor thermal environment.

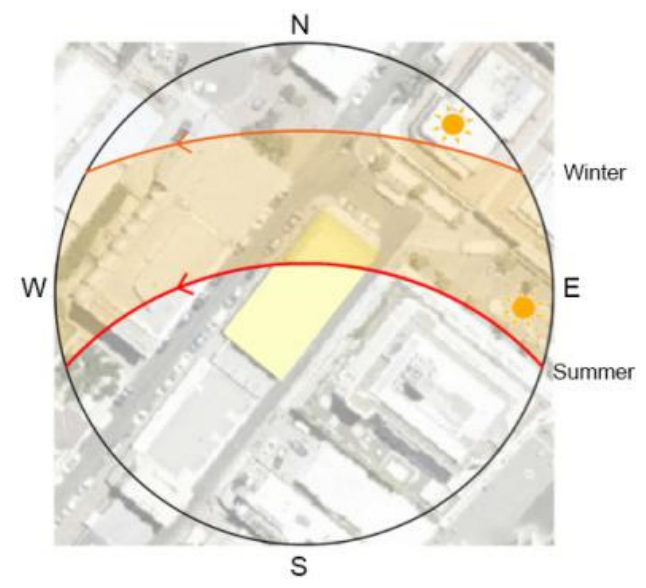

Fig1. Site orientation and year-round sunshine tracking range.

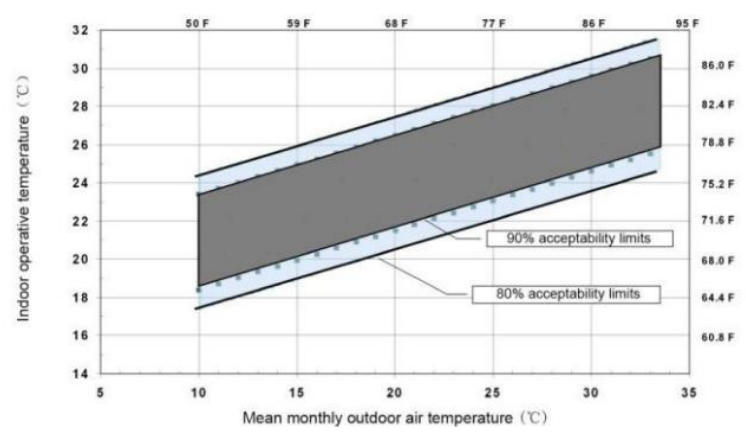

Fig2. Definition of the temperature range that corresponds to thermal comfort time in ASHRAE Standard.

\section{Influence of building facade on indoor thermal comfort}

Building facades are directly exposed to the external environment. Different building facades are related to varying indoor comfort and energy consumption levels. A reasonable facade design helps reduce energy consumption and improve indoor thermal comfort ${ }^{[7]}$. Therefore, the passive design of building facades is an important aspect in managing building energy consumption ${ }^{[8]}$.

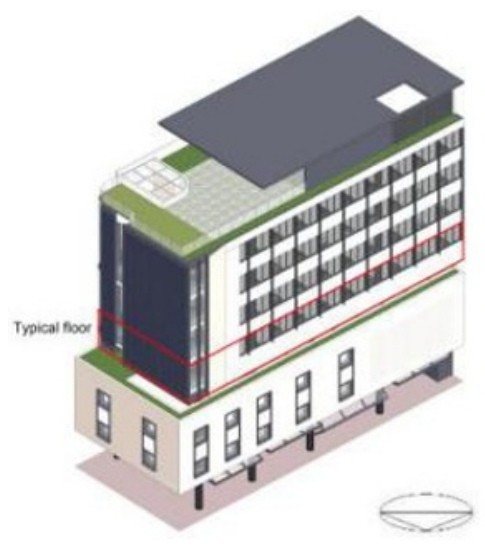

(a) Building model

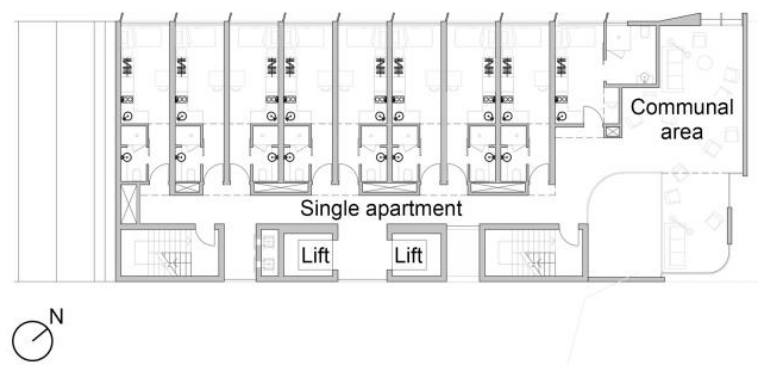

(b) Typical floor plan

Fig3. Building model and typical floor plan.

As shown in Figure 3(a), the building has a concrete frame structure with sand-coloured facing bricks. The ground floor is a whole open space for public services. The first and second floor contain an auditorium for 150 people and offices for community parties and meetings. The third and higher floors are typical floors for residences, where each floor is composed of eight single apartments and a public activity area. The building faces northwest; hence, an analysis of the typical floor plan of the original building shows that a considerable amount of solar radiation is absorbed in the afternoon. To reduce the accumulation of solar radiation, vertical shading devices are included in the original design, as shown in Figure 4.

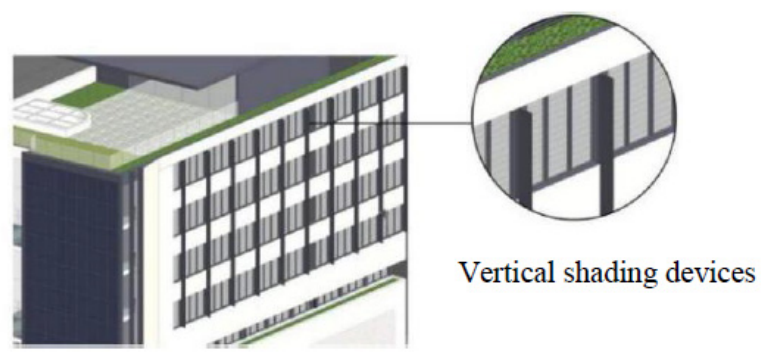

Fig4. Vertical shading devices on the original building.

In DesignBuilder, division is implemented based on the actual building design parameters and functions, and modelling is performed for the selected typical floor plan. 
The properties used in each area are defined, as shown in Figure 5(a). Simulation analysis on the indoor thermal comfort of the original building indicates that the major factor that influences indoor thermal comfort is the excessive accumulation of solar radiation through the facade, particularly through the external window, as shown in Figure 5.

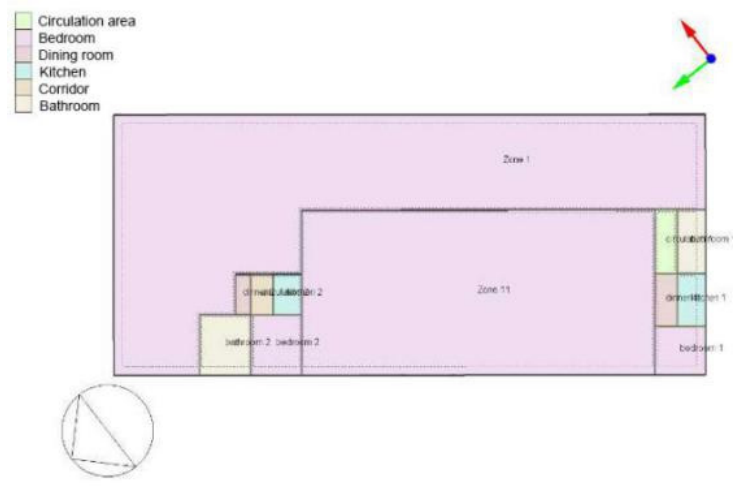

(a) Division of different areas based on a typical floor model

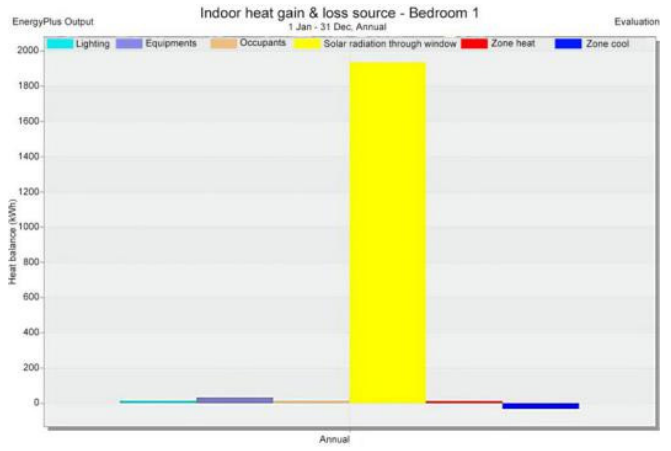

(b) Bedroom 1 Sources of heat gain and loss analysis

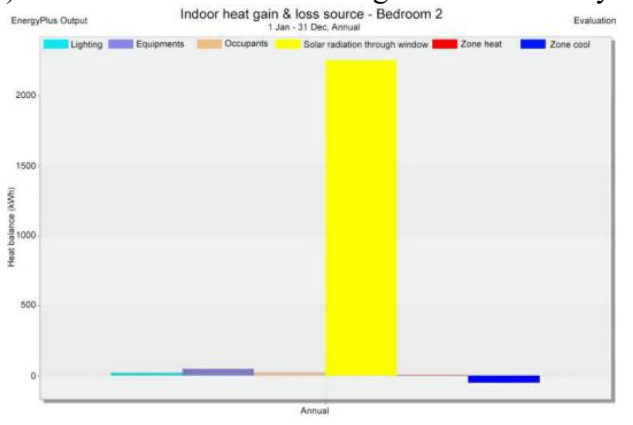

(c) Bedroom 2 Sources of heat gain and loss analysis

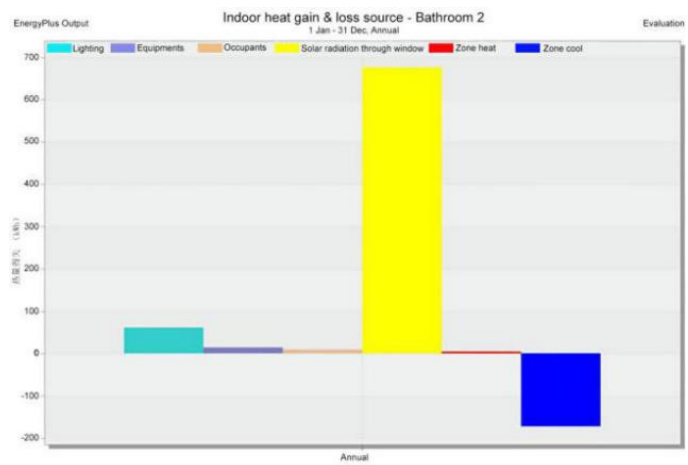

(d) Bathroom 2 Sources of heat gain and loss

Fig5. Simulation model of the original building and heat gain and loss.
On the basis of the building orientation and using unchanged functions, optimization design is implemented on elements of the typical floor facade, as shown in Figure 6. Optimization design includes replacing the common single glass with Low-E double glass for the external window, adding horizontal shading devices to the vertical shading devices, forming integrated shading devices and replacing facade materials to decrease the heat conductivity coefficient.

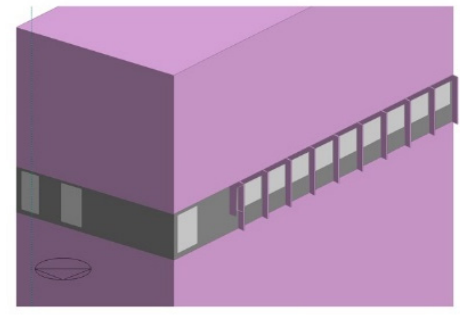

(a) Facade before optimization

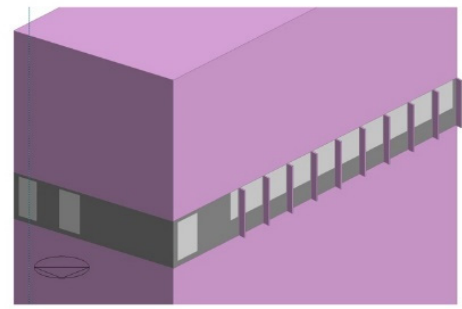

(b) Facade after optimization

Fig6. Facade before and after optimization.

\section{Passive design strategy on the facade}

The aforementioned simulation analysis of the original building indoor thermal comfort shows that heat that causes indoor thermal discomfort is mostly due to direct solar radiation through the facade. The optimization of passive design can effectively improve the heat-insulating performance of the external part of the building. The influence of indoor overheating due to direct solar radiation on indoor thermal comfort can be enclosed and reduced.

\subsection{Changing window glass type}

The original building uses a common single glass, which is similar to those used in most local residential buildings. Common single glass exhibits an evident shortcoming of having a high $U$ value $\left(5.88 \mathrm{~W} / \mathrm{m}^{2} \bullet \mathrm{K}\right)$ and cannot effectively block heat brought by long-wave light ${ }^{[9]}$. To reduce heat gain due to solar radiation, the optimization design adopts a Low-E glass coating, which demonstrates excellent thermal barrier effect and outstanding lightadmitting quality with a high reflection of mediumdistance and far infrared rays. After optimization (Figure 7 ), the air layer of Low-E double-layer glass is $13 \mathrm{~mm}$ thick, and the glass is $6 \mathrm{~mm}$ thick. The heat conductivity coefficient of the external window is reduced from 5.88 $\mathrm{W} / \mathrm{m}^{2} \cdot \mathrm{K}$ to $1.67 \mathrm{~W} / \mathrm{m}^{2} \cdot \mathrm{K}$ when the common single glass is replaced with Low-E double glass. As shown in Table 1, the heat gained through the external window after 
optimization is reduced, and the total time of indoor thermal discomfort for the entire year decreases from $6286.5 \mathrm{~h}$ to $5840.5 \mathrm{~h}$, which accounts for $7.1 \%$.

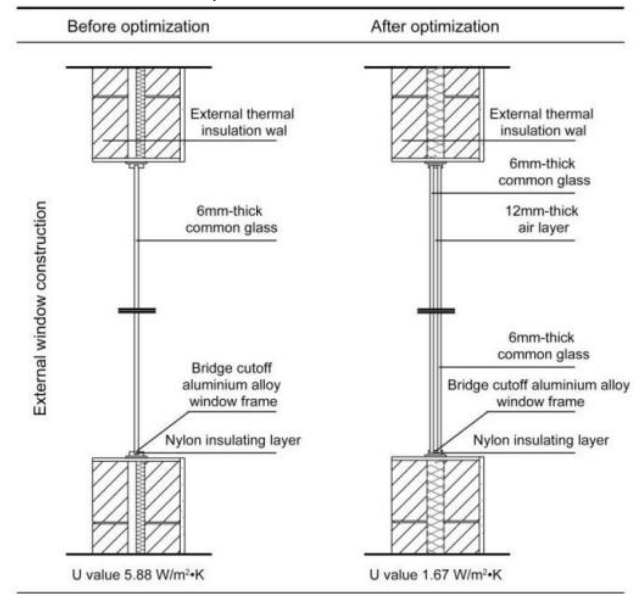

Fig7. Comparison of external window glass before and after optimization.

Table1. Comparison of time of indoor thermal discomfort.

\begin{tabular}{|c|c|c|}
\hline Space & $\begin{array}{c}\text { Before } \\
\text { optimization }\end{array}$ & $\begin{array}{c}\text { After } \\
\text { optimization }\end{array}$ \\
\hline Bedroom1 & 945.5 & 810 \\
\hline Bedroom2 & 335 & 220 \\
\hline Dining room 1 & 677.5 & 592.5 \\
\hline Dining room2 & 639.5 & 554.5 \\
\hline Kitchen1 & 531.5 & 498.5 \\
\hline Kitchen2 & 563 & 564 \\
\hline Corridor1 & 664 & 665 \\
\hline Corridor2 & 936 & 896.5 \\
\hline Bathroom1 & 619 & 639 \\
\hline Bathroom2 & 375.5 & 400.5 \\
\hline Total & 6286.5 & 5840.5 \\
\hline
\end{tabular}

\subsection{Addition of shading devices}

In addition to changing the external window glass type, installing reasonable shading devices on the external wall can also reduce the negative influence of solar radiation on indoor thermal environment. The simulation analysis indicates that using only the vertical shading method cannot provide a satisfactory shading effect; therefore, horizontal shading devices are added to the optimization design. Consequently, integrated shading is adopted. As shown in Figure 8, the horizontal and vertical shading baffles have a ledge size of $500 \mathrm{~mm}$. With the adoption of integrated shading based on the software simulation statistics, the total time of indoor thermal discomfort for the entire year is reduced by $186 \mathrm{~h}$, which accounts for $3 \%$.

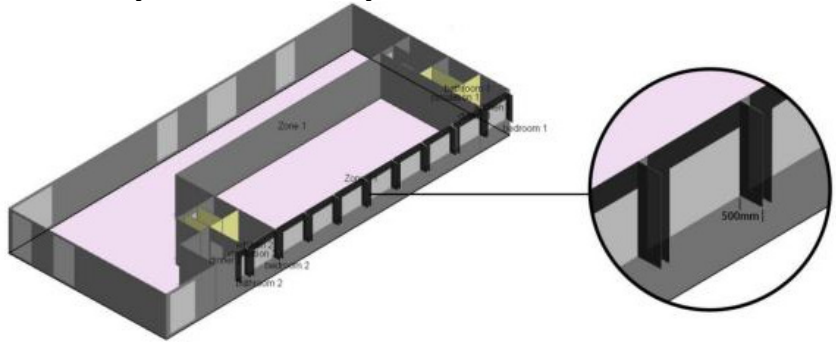

Fig8. Application of integrated shading devices on the facade after optimization.

\subsection{Optimization of building facade wall materials}

In addition to the window glazing and shading devices, another important element of the facade is the external wall. The entire building adopts a reinforced concrete structure, with double brick external walls and external thermal insulation. In the original building design, a 25 $\mathrm{mm}$ asbestos board insulating layer and a $25 \mathrm{~mm}$ air layer are adopted. With an increase in thermal insulating layer thickness, the thermal performance of the external wall can be improved to a certain degree. The thickness of the asbestos board insulating layer is increased from $25 \mathrm{~mm}$ to $50 \mathrm{~mm}$, thereby canceling the air layer, as shown in Figure 9. Hence, the thermal performance of the external wall is considerably improved. The simulation analysis on indoor thermal comfort after optimization indicates that the total time of indoor thermal discomfort for the entire year is decreased by $874 \mathrm{~h}$, which accounts for $14 \%$.

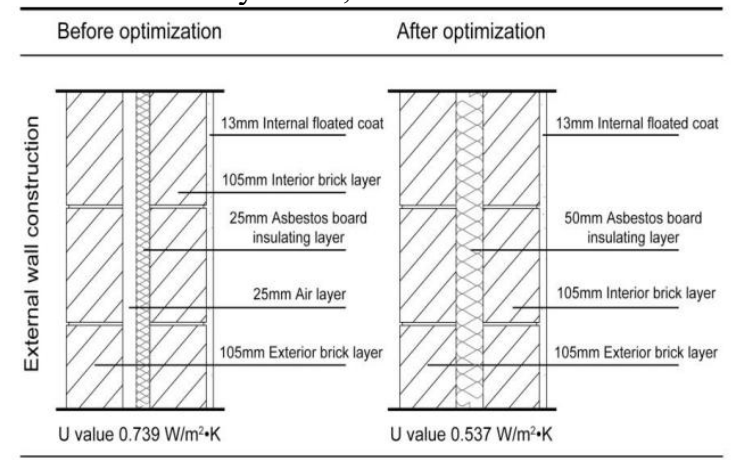

Fig9. Comparison of the exterior wall structure before and after optimization.

\section{Conclusion}

With the three passive designs on building facades, namely, double-layer Low-E glass, shading devices and exterior wall materials, the total time of indoor thermal discomfort for the entire year is reduced by $1,506 \mathrm{~h}$, which accounts for $24 \%$. When double-layer Low-E glass is used, the total discomfort time is reduced by $446 \mathrm{~h}$ (accounting for $29.6 \%$ in total reduction time). When shading devices are added, 
the total discomfort time is reduced by $186 \mathrm{~h}$ (accounting for $12.4 \%$ in total reduction time). When exterior wall materials with a low heat conductivity coefficient are used, the total discomfort time is reduced by $874 \mathrm{~h}$ (accounting for $58 \%$ in total reduction time). Therefore, the choice of external wall materials exerts a considerable influence on indoor thermal comfort. Furthermore, the indoor thermal comfort of existing buildings can also be improved by changing the external window glass type and adding shading devices. The results of this research provide a technical reference for local residential building design and construction.

\section{Acknowledgments}

This work has been supported by Jiangsu province university outstanding science and technology innovation team project.

\section{References}

1. .A.R. Lewis, E. David, Int. J. of Facility Management. (2010) , 1(2):145-156.

2. J Xiao, J Zhou, F Xu et al, J. of Central South University. (2012) , 43(9):3693-3697.

3. ZF Wu, LD Chen, J. of Ecology. (2016), 35( 5): 1364-1371.

4. HH Yin, Passive Design Strategy of Public Building Transition Space of climate in Areas Warm in Summer and Cold in Winter.D. Chongqing: Chongqing University, (2010)

5. Climate Data of Sydney. http://gb.weather.gov.hk/wxinfo/climat/world/chi/aus tralia/au/sydney_c.htm[EB/OL].

6. ASHRAE Standard 55- (2013) . Bondi Beach Climate, Averages And Extreme Weather Record[S].

7. A.Aksamija, ABER.J. (2015) , 10 (2): 240-262.

8. A.Aksamija, High-Performance Building Envelopes: Design Methods for Energy Efficient Facades.M. (2015)

9. HR Xie, Theoretical Analysis and Experimental Study on Energy Consumption of Filmed Window Glass .D. Changsha: Hunan University, (2007) 